\title{
The analysis of the possibilities of increasing the share of propane in the fuel mixture supplied to a dual fuel diesel engine
}

\begin{abstract}
The paper presents the main reasons for the limitations as to the share of gaseous fuel in dual fueling in commercial engine applications. It also indicates the proposals of solutions aiming at increasing of the share of this fuel. The investigations were conducted in two stages. The first stage of the investigations involved gradual increase in the share of propane at a simultaneous phasing out of the amount of diesel fuel so that the excess air coefficient remained on the same level. The second stage of the investigations involved a maximum possible share of propane with a simultaneous adjustment of the diesel fuel injection parameters. The investigations were performed for three different values of the charging pressure: 200, 400, 600 mbar and for a naturally aspirated variant. The obtained results led to a conclusion that modifying diesel fuel injection parameters and increasing the charging pressure allow a significant increase in the share of gaseous fuel up to $70 \%$ of the total energy contained in both fuels.
\end{abstract}

Key words: dual fuel, supercharged engine, propane, combustion process, exhaust emissions

\section{Introduction}

The concept of duel fuel engine fueled with diesel fuel and an additional fuel of low cetane number (propane, LPG, methane, ethanol, gasoline) assumes the greatest possible share of the additional fuel in the combusted mixture. Solutions already exist, in which the energy share of the additional fuel reaches $99 \%$. These solutions, however, are used in large powertrains usually applied in marine transport. The solutions that enable using such great share of additional gaseous fuel (most often natural gas) have not yet been loaned to smaller units used in road transport. The specificity of transport of liquefied gas by sea forced the necessity to utilize the evaporated part of gas, which is a natural consequence of gas in a liquid state. This is how gas has become a fuel powering the engines of a transporting vessel. An additional benefit resulting from this type of fueling is the improvement of the environmental performance mainly by a reduction of the emission of particulate matter $[5,6,8,10,14]$. The economic factor is also important due to the difference in the prices of diesel oil and gaseous fuels. There is little wonder that the number of duel fuel vehicles is growing. This is particularly the case for heavy-duty vehicles. Compared to passenger vehicles or light duty trucks there are no stringent limitations as to the location of the additional fuel cylinder, hence the lower percentage share of the weight of such a fuel tank in the weight of the vehicle, particularly if steel high-pressure gas containers are applied. Besides, the need to reduce the costs of operation appears to be a decisive factor if a dual fuel system is to be installed. Given the difference in the prices of diesel fuel and the mixture of propane/butane that can successfully be applied in dual fuel systems, a well developed network of distribution, easy transport and storage make it a very attractive source of energy resulting in a growing number of users of duel fuel systems [3]. Current solutions used in motor vehicles, however, allow a mere $30 \%$ energy share of LPG, which, from the economic point of view is less attractive and distant from the solutions offered for marine transport. Hence, comes the question of the reason for the fact that the share of energy obtained from additional fuel is not as significant as it should be and whether the limitation responsible for such a status quo may perhaps be eliminated without the need of costly modifications of the power train. For many years, research on this type of fueling has been dealing with analyses of the phenomena occurring during the process of combustion in dual fuel engines $[4,9,14]$. This contributed to solving problems characteristics of duel fueling - the course of the combustion process. The aim of this paper is to indicate the main reasons for the limitation of the share of additional LPG fuel and propose solutions that would enable increasing this share.

\section{Research procedure}

The investigations were carried out on a $511 \mathrm{~cm}^{3}$ dual fuel (diesel fuel and propane) single cylinder diesel research engine (AVL 5402) of the compression ratio of $\varepsilon$ 17.5 Fig. 1. In the investigations, the most commonplace system of supply of indirectly injected evaporated propane was used. The gas was fed via an injector fitted near the intake valve. The opening time of the injector was synchronized with the cylinder filling cycle, which prevented the loss of cylinder charge at valve overlap [12]. The investigations were performed in two stages. The first stage consisted in a gradual increase in the share of propane with the diesel fuel being phased out to keep the excess air coefficient on a steady level. The investigations were performed for three different charging pressures: 200, 400, 600 mbar and for the naturally aspirated variant. The parameters of the injection of diesel fuel such as pressure, start of injection of the pilot and the main doses were constant irrespective of the share of propane in the mixture or the variations in the charging pressure, which corresponded to the original settings applied in diesel fueling alone. Only the value of the main fuel dose was changed, which resulted from the need to maintain a steady level of excess air coefficient at the moment of increasing of the share of propane in the mixture. The increase in the share of propane with the reduction of the share of diesel fuel was continued until the maximum pressure increment exceeded $1 \mathrm{MPa} / \mathrm{deg}$. The second stage of the investigations consisted in applying the greatest possible share of propane for different levels of the charging pressure, as in the first stage, with a simultaneous 
adjustment of the injection parameters of diesel fuel still preserving the above-mentioned criterion of pressure increment rate and the highest possible overall engine efficiency.

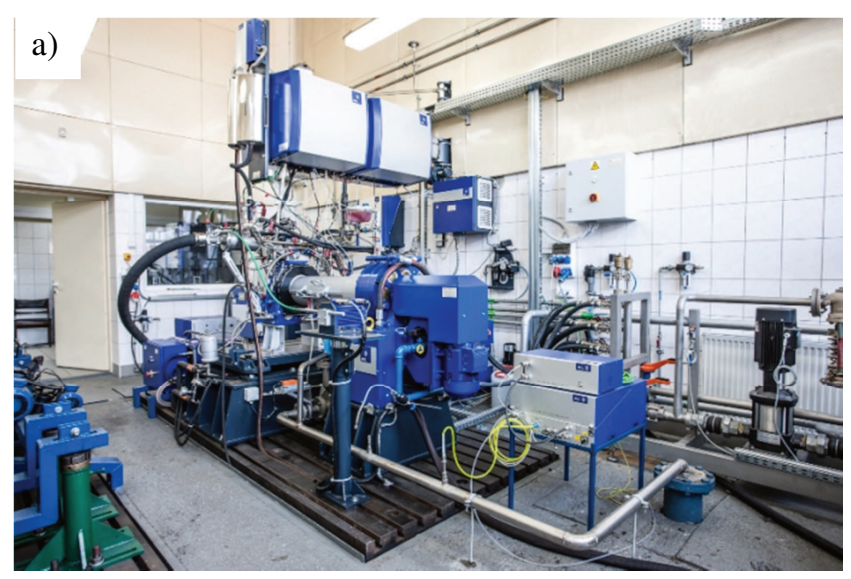

b)

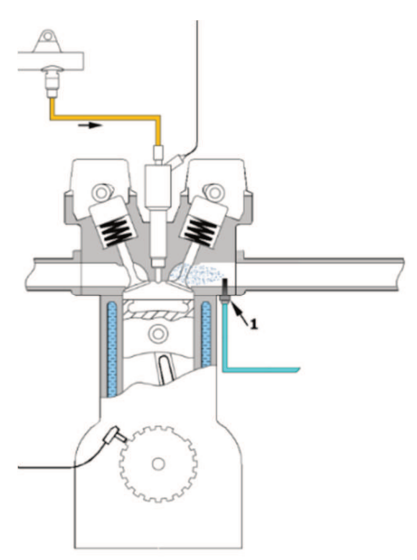

Fig. 1. a) Engine dynamometer by AVL, b) The method of propane supply to the engine

\section{Possibilities of increasing of the share of propane in the mixture of fuels while preserving the excess air coefficient}

As earlier research has shown, the main limitation for high shares of propane is the abruptness of the course of combustion that is characterized by a high pressure increment rate, much more exceeding the values obtained for diesel fuel alone. By gradually increasing the share of propane and reducing the share of diesel fuel while maintaining the injection parameters optimum for conventional fueling (performance of the first stage of the investigations), one can observe a clear growth of the maximum pressure increment rates Fig. 2. The maximum share of propane for which this parameter did not exceed $1 \mathrm{MPa} / \mathrm{deg}$ is merely $30 \%$ for the naturally aspirated engine and $50 \%$ for the highest charging pressure applied during the investigations. When analyzing the influence of the share of propane on the pressure increment rate, one can clearly observe that the addition of propane for all cases under analysis results in an increase in the pressure increment rate and a delayed self-ignition. The physicochemical changes of the compressed mixture of propane and air more significantly influence the delay of the start of combustion when the share of the gaseous fuel is greater Fig. 3. The increase in the share of the gaseous fuel is accompanied by the increase in the specific heat of the compressed mixture [12-14], the effect of which is a lower temperature of the medium in the compression phase leading to a delay in the start of combustion. The lower concentration of oxygen in the compressed mixture, being a consequence of the portion of propane fed to the cylinder, is another reason for the delay of the start of combustion. Hence, the growing delay of ignition will directly affect the pressure increment rate in the combustion process because a significant portion of energy coming from the pilot dose of diesel fuel and part of the dose of propane is released in a shorter time compared to conventional fueling $[1,6,15,16]$. Changes in the pressure increment rate in the combustion process are tightly related to the changes of the charging pressure. Maintaining the parameters of diesel fuel injection, the excess air coefficient and increasing the charging pressure one may observe a very conspicuous and at the same time advantageous phenomenon. An increase in the charging pressure results in a reduction of the maximum pressure increment rates. This means that the disadvantageous consequences following the addition of propane can be eliminated by a change in the charging pressure. According to the theory contained in [2], an increase in the charging pressure results in a growth of the temperature of the compressed mixture, thus, a reduction of the delay in self-ignition. Consequently, it causes a less abrupt course of combustion, the result of which is a drop in the maximum pressure increment rates. Wherever the delay of self-ignition grows distorting the combustion process, it is possible to influence that by increasing the charging pressure. For the naturally aspirate variant, a merely $30 \%$ share of propane gave average values (from the recorded test cycles) of the pressure increment rate of $8.9 \mathrm{bar} / \mathrm{deg}$ and, at times, exceeding $15 \mathrm{bar} / \mathrm{deg}$. Therefore, the increase in the share of propane under these conditions should not be continued mainly due to the risk of damaging the engine, which is why the authors gave up supplying more gaseous fuel to a naturally aspirated engine. The presented $70 \%$ share of propane was obtainable only after changing the parameters of the diesel fuel injection exclusively in the turbocharged engine. The most conspicuous effect of the impact of the charging pressure on the pressure increment rate can be seen on the example of the $30 \%$ share of propane, for which the charging pressure from 0 to 600 mbar resulted in almost a double reduction of the pressure increment rate. When analyzing the parameter of maximum pressure increment rate, which is the fundamental criterion in selecting the shares of both fuels, one has to note the very desired effect of reduction of the pressure increment rates following the increase in the charging pressure. Maintaining the excess air coefficient on the same level when increasing the charging pressure must lead to an increase in the amount of energy supplied with the fuel. Despite the greatest portion of energy for the case of the maximum charging pressure, the maximum pressure increment rates are the lowest and even though this parameter increases with the growing share of propane, the increment is the smallest out of all the cases under analysis. 


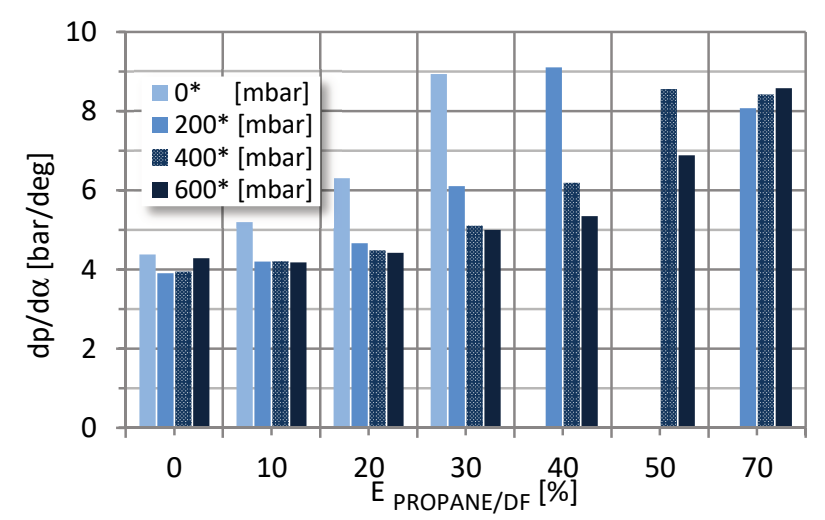

Fig. 2. Maximum pressure increment rates for conventional fueling and dual fueling with a growing share of propane for 4 values of the charging pressure

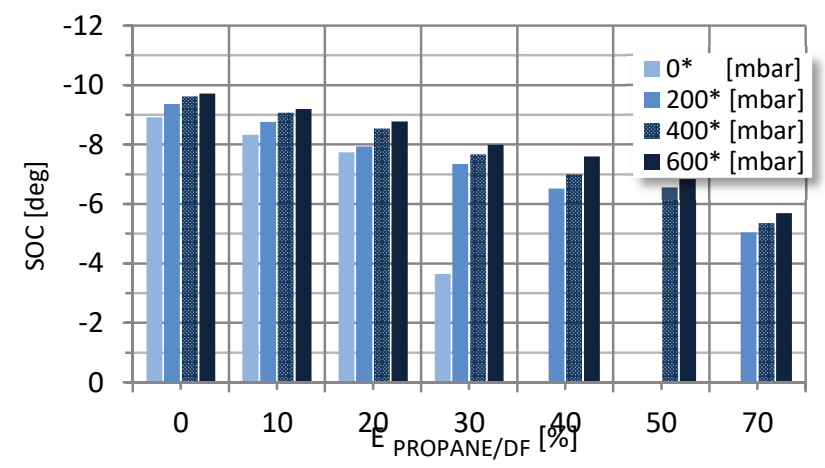

Fig. 3. Start of combustion for conventional fueling and dual fueling with a growing share of propane for 4 values of the charging pressure

The dropping trend of the maximum pressure increment rates following the increase in the charging pressure continues starting from a $10 \%$ and ending with a $50 \%$ share of propane except the greatest $(70 \%)$ share of this gas, for which the parameters of the diesel fuel injection were modified. When analyzing the pressure curves inside the cylinder for different shares of propane Fig. 4., one can see a clear impact of the changed thermodynamic properties of the compressed mixture. Following the increase in the share of the gaseous fuel, one can observe a gradual decrease of the pressure of the charge in the compression phase. Since this trend is maintained in all the cases under analysis, only the results obtained for the highest charging pressure $(600$ mbar) have been presented Fig. 4. The lower pressure of the compressed mixture, the lower temperature at the moment of injection of the pilot fuel dose and the lower oxygen concentration in the compressed mixture due to the growing amount of propane pushing out the air fed to the cylinder result in a clear delay of the start of combustion, thus influencing the heat evolution curves shown in Fig. 5.

Comparing the course of combustion obtained for conventional fueling with the course of combustion for duel fueling, it can be confirmed that the growing share of the gaseous fuel clearly influences the first phase of the combustion, in which the pilot dose plays an important role. For conventional fueling, the pilot fuel dose, whose start o injection is at $18^{\circ}$ before TDC, definitely initiates the process of combustion as can be seen on the graph of the cyl- inder pressure curve Fig. 4. and on the heat evolution curve Fig. 5. The increase in the share of the gaseous fuel results in a much different start of combustion and heat evolution rate in the initial phase of the combustion process compared to diesel fuel alone. When a small (10\%) share of propane results in a small $\left(0.5^{\circ}\right) \mathrm{CA}$. self-ignition delay compared to conventional fueling and the heat evolution curve has two phases, the $50 \%$ share results in a delayed start of combustion by $3^{\circ}$ and the boundary between the phases of the combustion process fades Fig. 5. This means that along the increase in the share of propane, despite the growing delay in self-ignition, the portion of energy released in the initial phase of the combustion process (started by the pilot dose) is much greater than that obtained for diesel fuel alone. The consequence is the increase in the charge-burning rate Fig. 6 . and a shift of the peak value of the pressure towards TDC Fig. 4.

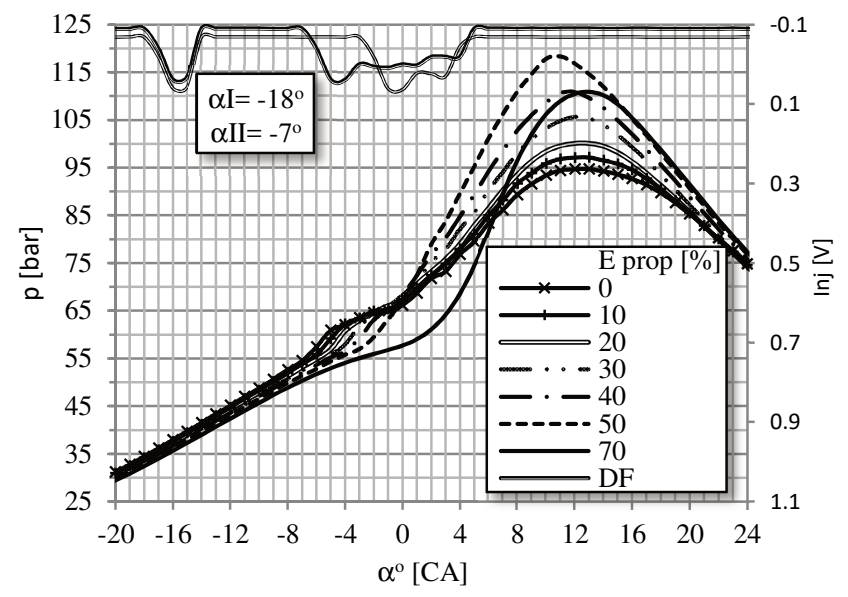

Fig. 4. Pressure curves taken from inside the cylinder for conventional fueling and dual fueling with a growing share of propane for the charging pressure of 600 mbar. Angle of the start of injection of the pilot fuel dose $-18^{\circ}$, angle of the start of injection of the main fuel dose $-7^{\circ}$ (constant for the $0 \%-50 \%$ share of propane), angle of the start of injection of the main fuel dose $-3^{\circ}$ (for the $70 \%$ share of propane)

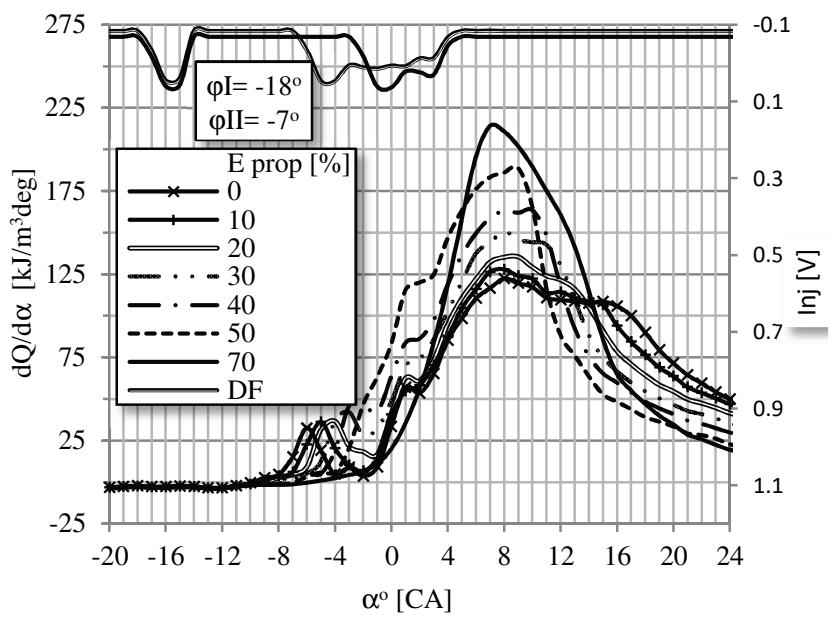

Fig. 5. Heat evolution curves taken from inside the cylinder for conventional fueling and dual fueling with a growing share of propane for the charging pressure of 600 mbar. Angle of the start of injection of the pilot fuel dose $-18^{\circ}$, angle of the start of injection of the main fuel dose $-7^{\circ}$ (constant for the $0 \%-50 \%$ share of propane), angle of the start of injection of the main fuel dose $-3^{\circ}$ (for the $70 \%$ share of propane) 


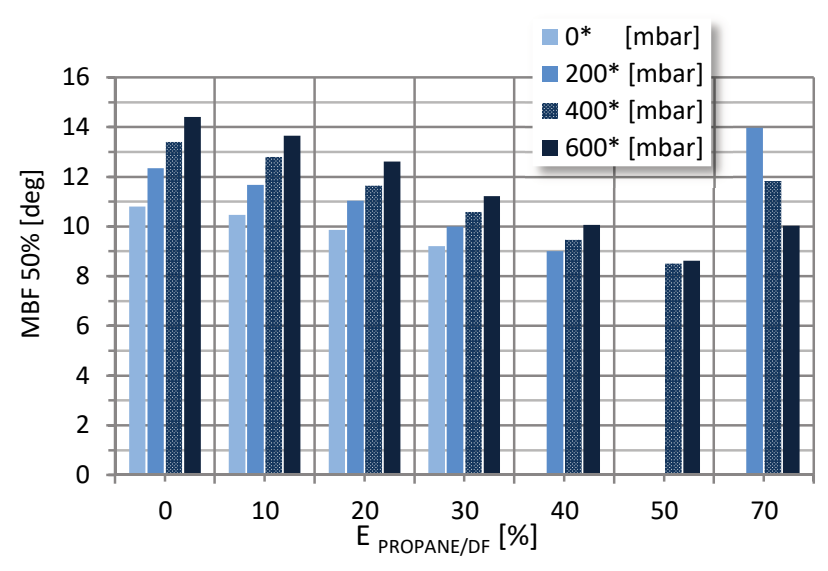

Fig. 6. Burning of $50 \%$ of the charge for conventional fueling and dual fueling with a growing share of propane for 4 values of the charging pressure

Analyzing the course of the combustion process based on the charge burn described with a $50 \%$ burn in the scale of CA. Fig. 6. a diversity is observed compared with the first phase of the combustion process Fig. 3, where the increase in the share of propane resulted in a delay of the self-ignition in all cases under analysis and the phase of the charger half-burn indicates a significant growth of the combustion dynamics. This process is almost linear; the trend of growth of the charge burn intensity clearly depends on the proportions of both fuels and the charging pressure. Only in the case of the highest $(70 \%)$ share of propane was this process different, which resulted mainly from: the combination of the influence of a significant share of propane, the influence of the changes of the charge temperature and the delay of the angle of the start of diesel fuel injection. The greatest differences in the time needed to burn $50 \%$ of the charge were for conventional fueling. The increase in the share of the gaseous fuel gradually reduces these differences. From the analysis of the above graph, one may infer that along the increase in the charging pressure, the combustion time extends. This phenomenon is to be explained by the fact that the growing charging pressure is tantamount to the increase in the amount of fuel (maintaining constant excess air coefficient), thus, to the prolonged reactions accompanying the combustion process. Hence, when maintaining the injection pressure and the angle of the start of injection of the pilot fuel dose, it is necessary to extend the duration of the injection of the diesel fuel. A greater portion of injected fuel at a decreasing difference of the pressures (higher compression and constant injection pressure) caused by the growing pressure inside the cylinder due to supercharging translates into a deteriorated atomization, therefore leading to the extension of the time of combustion. A substitution of part of the conventional fuel with gaseous fuel accelerates the combustion process and the differences in the time to burn $50 \%$ of the charge for different charging pressures become less clear Fig. 6. Burning of $50 \%$ of the charge with a $50 \%$ share of propane despite a late start of combustion falls at approx. $8.5^{\circ}$ after TDC i.e. almost $6^{\circ}$ earlier compared to diesel fueling alone. As a consequence, this leads to an increase in the maximum pressure increment rates, increase in the maximum pres- sures of the combustion process and a shift of the peak pressure towards TDC.

The changes that are observed in the course of the combustion process under conventional and dual fueling become so conspicuous that they may have impact on the actual use of such an engine. As a consequence, this may lead to an accelerated wear of components due to excess mechanical and thermal loads. A question arises, whether it is possible to increase the share of the gaseous fuel at a simultaneous preservation of the overall efficiency and the combustion parameters obtained under conventional fueling. The fact that no engine modifications are performed before the increase in the share of the gaseous fuel is also significant. The performed investigations have shown that the objective is to delay the combustion process in duel fueling so that the parameters of this process such as the maximum pressure increment rates and the maximum pressure are not significantly divergent from the ones of conventional fueling. The fulfillment of these conditions will eliminate the risk of premature engine wear. The application of a common rail based fuel system allows a very precise control of the course of combustion by the possibility of a very extensive change of the diesel fuel injection parameters. In dual fueling it is very important to be able to control the way of releasing the energy contained in the gaseous fuel. The application of a great share of the gaseous fuel and the introduction of a single ignition-initiating fuel dose of the compressed mixture is characterized by a very abrupt nature of the combustion process including knock combustion. [9, 13] A properly selected angle of the start of injection for conventional fueling will not be optimum for dual fueling. The introduction of the possibility of dividing of the diesel fuel dose, however, makes the process of combustion in a dual fueling scenario (even with the 70\% share of propane) less abrupt than the combustion with a $30 \%$ share of propane with a single dose of diesel fuel. Besides, the possibility of a precise adjustment of the pilot and the main fuel doses and the angle of the start of injection of these fuel doses results in a situation that despite significant differences between the conventional and dual fueling combustion, it is possible to eliminate disadvantageous phenomena such as: knock combustion, limitation of the maximum pressure increment rates and maximum pressure.

\section{Investigating the possibilities of reaching the greatest share of propane in the mixture of fuels for different charging pressures with adjustment of diesel fuel parameters}

In the second stage of the investigations, the authors attempted to increase the energy share of propane while reducing the share of diesel fuel. The maximum share that was applied was $70 \%$ of propane for three charging pressures: 200, 400, 600 mbar and 50\% for the naturally aspirate variant. The selection of such propane to diesel fuel ratio was not a coincidence and was determined by a series of previously performed trials that allowed indicating a safe boundary of the share of the gaseous fuel. Similarly to the first part of the investigations, the fundamental criterion was the maximum pressure increment rate whose value should not exceed $1 \mathrm{MPa} / \mathrm{deg}$. In order to meet this condi- 
tion, the angle of the start of injection of the diesel fuel had to be delayed. The presented results in the form of the pressure (Fig. 7) and the heat evolution (Fig. 8) curves pertain to cases with the most beneficial adjustment of the angle of the start of injection of both the pilot and the main fuel doses that led to the obtainment of the highest overall efficiency of the investigated engine.

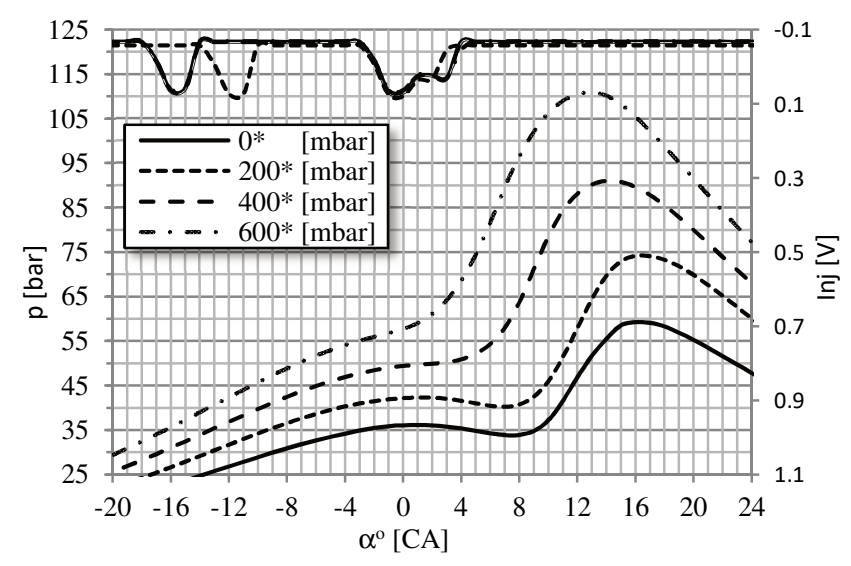

Fig. 7. Cylinder pressure curves for dual fueling with a $70 \%$ share of propane for three different charging pressures 200, 400, $600 \mathrm{mbar}$ ad for the naturally aspirated variant with a $50 \%$ share of propane with the introduced change of the angle of the start of injection of the pilot and the main fuel doses

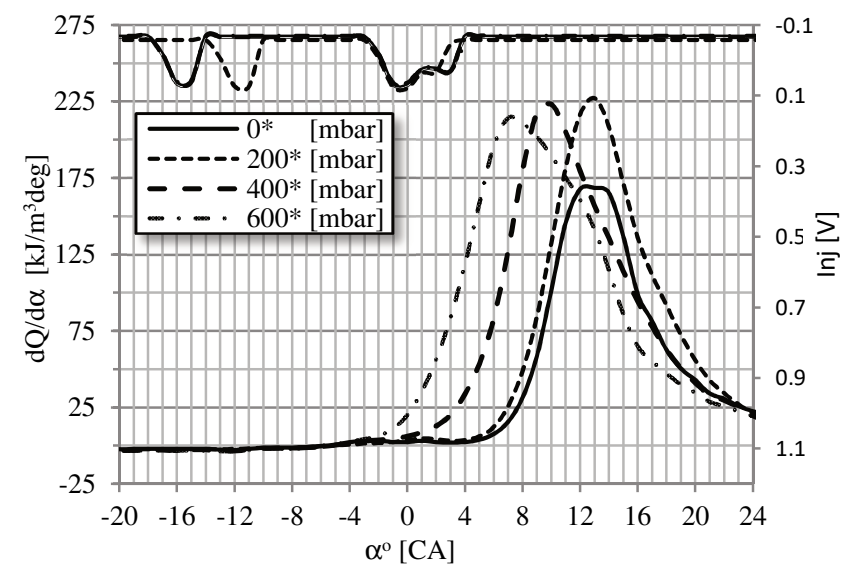

Fig. 8. Heat evolution curves for dual fueling with a $70 \%$ share of propane for three different charging pressures 200, 400, $600 \mathrm{mbar}$ ad for the naturally aspirated variant with a $50 \%$ share of propane with the introduced change of the angle of the start of injection of the pilot and the main fuel doses

At the charging pressure of 600 mbar, the angle of the start of injection of the main fuel dose was changed from $-7^{\circ}$ to $-3^{\circ}$. This delayed the course of combustion, prevented the excess of the maximum pressure increment rate and limited the maximum pressures by approx. 10 bar compared to the maximum pressures obtained for the $50 \%$ share of propane without modifying the injection parameters. The application of such a great share of propane resulted in a $1 \%$ drop of the overall efficiency compared to conventional fueling, the reason for which may have been: greater heat loss (higher temperatures in the combustion process, greater heat release area), escape of part of the gaseous fuel due to valve overlap and incomplete combustion of part of pro- pane particularly in the area where diesel fuel had no access because of limited spray penetration. A small drop in the overall efficiency has been observed for the other variant of the charging pressure. Because of the similar nature of the course of combustion, the reasons for deterioration of the efficiency will also be similar. Another analyzed case for the charging pressure of 400 mbar indicates a need of maintaining the same angles of the start of injection of the main fuel dose only. Similarly to the higher charging pressure, a small drop in the efficiency is observed. For the pressure of 200 mbar the angle of the start of injection of both the pilot and the main dose was changed. A small delay in the injection of the pilot fuel dose gives it a greater chance of taking on the combustion due to a higher temperature of the medium, to which it is fed. A change of this parameter appears justified, particularly if, following the growing share of propane, the temperature of the compressed medium drops, which was discussed in the first part of the investigations. Out of the analyzed cases, the most beneficial is the one with the highest charging pressure. When analyzing the course of combustion it may be indicated that for both the conventional and dual fueling, the peak value of pressure occurs in the same position of the crankshaft (approx. $12^{\circ}$ after TDC). In the other supercharging variants the maximums of the pressures drift from the TDC, thus shifting the center of the combustion process, the consequence of which is a slight drop in the efficiency compared to the efficiency obtained for diesel fueling only. Despite the fact that the change in the angle of the start of injection of the main fuel dose is capable of accelerating this process, it cannot be applied due to the accompanying increase in the maximum pressure increment rates exceeding the assumed value of 1 $\mathrm{MPa} / \mathrm{deg}$.

Despite significant differences in the course of combustion for the conventional and dual fueling variants, it is possible to control the fuel combustion in such a way that even a $70 \%$ share of propane does not result in a significant drop in the efficiency or excess pressure increment rate. For the naturally aspirated engines, the obtainment of such a great share of propane was impossible. The combustion process with the share of propane above $50 \%$ was characterized by a significant unrepeatability, a clear delay of combustion or even combustion deficiency. The attempt of an earlier initiation of combustion by changing the angle of the start of injection led to an increase in the maximum pressure increment rates and a 'jagged' pressure curve taken from inside the cylinder, which is characteristic of knock combustion. Therefore, despite corrections of the injection parameters widely implemented for the pilot and the main fuel doses, the maximum share of propane while still maintaining proper engine operation was $50 \%$. This means that for dual fueling in the naturally aspirated variant, the range of influence on the course of the combustion by a modification of the angle of the start of diesel fuel injection is significantly limited compared to the turborcharged version of the engine.

\section{Conclusions}

Because of the way the fuel is supplied to the cylinder in a dual fuel system, the formation of mixture subjected to high temperatures in the compression process and, addi- 
tionally, no diesel fuel dose division (diesel fuel initiates the ignition), the energy share of the additional fuel does not exceed $30 \%$. The performed investigations related to dual fueling have shown that a significant increase in the share of the gaseous fuel (propane or a mixture of propane and butane) is possible up to the level of $70 \%$. With such a significant share of propane used in the tests, the main limitation was the pressure increment rate.

The potential of modern common rail systems such as fuel dose division, adjustment of the amounts of these fuel doses and the pressure of their injection make the process of energy release a gradual one, hence, it is possible to eliminate the adverse effects such as excess pressure incre- ment rate, or excessively delayed start of combustion. With such high amounts of the gaseous fuel in the mixture, an adjustment of parameters of the diesel fuel injection is necessary. Besides, during dual fuel combustion with great shares of propane, an increase in the charging pressure gives very good results. It could, thus, be clearly stated that a combination of the adjustment of the diesel fuel injection parameters and the adjustment of the charging pressure provides a wide range of opportunities influencing the course of combustion if a great share of the gaseous fuel is the case, which ensures an effective combustion of two types of fuel in a compression ignition engine.

\section{Nomenclature}

CI compression ignition

LPG liquified petrolum gas

DF diesel fuel
TDC top dead center

SOC start of combustion

MBF mass burned fraction

\section{Bibliography}

[1] KYUNGHYUN, R. Effects of pilot injection timing on the combustion and emissions characteristics in a diesel engine using biodiesel-CNG dual fuel Appl. Energy. 2013, 111, 721-730.

[2] LEE, J., CHOI, S., KIM, H. et al. Reduction of emissions with propane addition to a diesel engine Int. J. Automotive Technol. 2013, 14(4), 551-558.

[3] LE FEVRE, C. The prospects for natural gas as a transportation fuel in Europe. Oxford Institute for Energy Studies paper NG84, March 2014.

[4] LUFT, S. Analysis of combustion process in a dual-fuel compression ignition engine fuelled with LPG in liquid phase. J. KONES Power Train Transp. 2007, 14(4).

[5] OGAWA, H., ZHAO, P., KATO, T., SHIBATA, G. Improvement of combustion and emissions in a dual fuel compression ignition engine with natural gas as the main fuel. SAE Technical Paper. 2015, 2015-01-0863.

[6] PAPAGIANNAKIS, R.G., HOUNTALAS, D.T. Theoretical study of the effects of pilot fuel quantity and its injection timing on the performance and emissions of a dual fuel diesel engine. Energy Convers. Manage. 2007, 48, 2951-2961.

[7] PAYKANI, A., KAKAEE, A-H., RAHNAMA, P., REITZ, R.D. Effects of diesel injection strategy on natural gas/diesel reactivity controlled compression ignition combustion. Energy. 2015, 90, 814-826.

[8] RAO, G.A., RAJU, A.V.S., MOHAN RAO, C.V., GOVINDA RAJULU, K. Effect of LPG content on the performance and emission characteristic of a diesel-LPG dual fuel engine. Eng. Today Quart. J. 2010, 2(4), 69-74.

Tomasz Skrzek, DEng. - Mechanical Engineering Faculty at Radom University of Technology and Humanities.

e-mail: T.Skrzek@uthrad.pl
[9] RÓŻYCKI, A. Analysis of performances of a dual-fuel turbocharged compression ignition engine. Journal of KONES Powertrain and Transport. 2010, 17(3).

[10] SAYIN, C, CANAKCI, M. Effects of injection timing on the engine performance and exhaust emissions of a dual-fuel diesel engine. Energy Conversion and Management. 2009, 50.

[11] SELIM MOHAMED, Y.E. Sensitivity of dual fuel engine combustion and knocking limits to gaseous fuel composition. Energy Convers. Manage. 2004, 45, 411-425.

[12] SKRZEK, T. Assessment of the effect of gaseous fuel delivery mode on thermal efficiency and fuel losses during the valve overlap period in a dual-fuel compression ignition engine IOP Conf. Series: Materials Science and Engineering 2016, 148.

[13] SKRZEK, T. Effect of the diesel fuel dose division and the injection angle on operating parameters of a dual-fuel compression ignition engine. Combustion Engines. 2015, 162(3), PTNSS-2015-3480.

[14] STELMASIAK, Z., MATYJASIK, M. Exhaust emissions of dual fuel self-ignition engine with divided initial dose. Combustion Engines. 2013, 154(3), 144.

[15] STELMASIAK, Z. The combustion controlling in the dual fuel CI engine by pilot dose division. Combustion engine. 2011, 146(3).

[16] WIERZBICKI, S. Effect of the parameters of pilot dose injection in a dual fuel diesel engine on the combustion process. Journal of KONES Powertrain and Transport. 2011, 18(3), 499-506. 